\title{
Cerebral Metastasis Revealing a Choriocarcinoma: Case Report
}

Toufga Zakaria' ${ }^{1 *}$, Touarsa Firdaous ${ }^{1}$, Marzouk Basma $^{2}$, Fikri Meriem ${ }^{1,3}$ and J iddane Mohamed ${ }^{1,3}$ ${ }^{1}$ Department of Neuroradiology, Mohammed V University, Morocco

${ }^{2}$ Department of Neurology, Mohammed V University, Morocco

${ }^{3}$ Faculty of Medicine and Pharmacy, Mohammed V University, Morocco

*Corresponding author: Zakaria Toufga, Department of Radiology, Military Training Hospital Mohamed V, Faculty of Medicine and Pharmacy University Mohammed V, Avenue of FAR, Hay Riyad, 10100, Rabat, Morocco

Received: November 30, 2017; Accepted: December 18, 2017; Published: J anuary 04, 2018

\section{Introduction}

Choriocarcinoma is a malignant and very aggressive form of gestational trophoblastic diseases characterized by a highly metastatic potential; brain metastasis is associated with poor prognosis. In this case report, we show the importance of early diagnosis of choriocarcinoma to limit dramatic complications.

\section{Case Description}

A 19-year-old woman, married, on oral contraception, having a history of an abortion 6 months ago, admitted for a sudden consciousness disorder. The patient had had progressive worsening headaches over 2 weeks, resistant to analgesic treatment.

The clinical examination denoted a GCS of 9 , a temperature at $37^{\circ} \mathrm{C}$, a heart rate at 105 beats $/$ minute, a respiratory rate at 25 cycles/minute, a bloodpressureat 170/100andanoxygensaturationat $90 \%$ inambientair. A cerebral computed tomography (CT) showed the presence of multiple hemorrhagic localizations in both sides of the frontal and parietal lobes; and the right occipital lobe; all of them are surrounded by significant peri-lesional edema.

Cerebral Magnetic Resonance Imaging (MRI) showed that these hemorrhagic localizations corresponded to heterogeneous hyper signal in T1, T2, FLAIR and diffusion (Figure 1), (Figure 2a,c,d); surrounded by a hypo-signal corona on $\mathrm{T} 2$ sequences with peripheral enhancement after gadolinium injection (Figure 2b).

The results of the MRI suspected secondary brain lesions that led us to perform a pelvic ultrasound and a thoraco-abdomino-pelvic CT scan which showed a globular uterus with the presence of a partitioned mass.

The Beta-HCG blood test revealed a rate of $500000 \mathrm{IU} / \mathrm{L}$.

After the 2nd chemotherapy treatment the patient became neurologically and respiratory impotent and died of severe respiratory failure (Figure 2a,b).

\section{Discussion}

Choriocarcinoma is a very aggressive malignant form of gestational trophoblastic disease characterized by high metastatic potential; its incidence was estimated to 0.18 per 100,000 women between the ages of 15 and 49 in the United States [1]; in Morocco, on a series of 105 cases of trophoblastic diseases, 24 cases of choriocarcinoma were reported, i.e., a rate of $22 \%$ [2].

Several risk factors have been described, including age older than
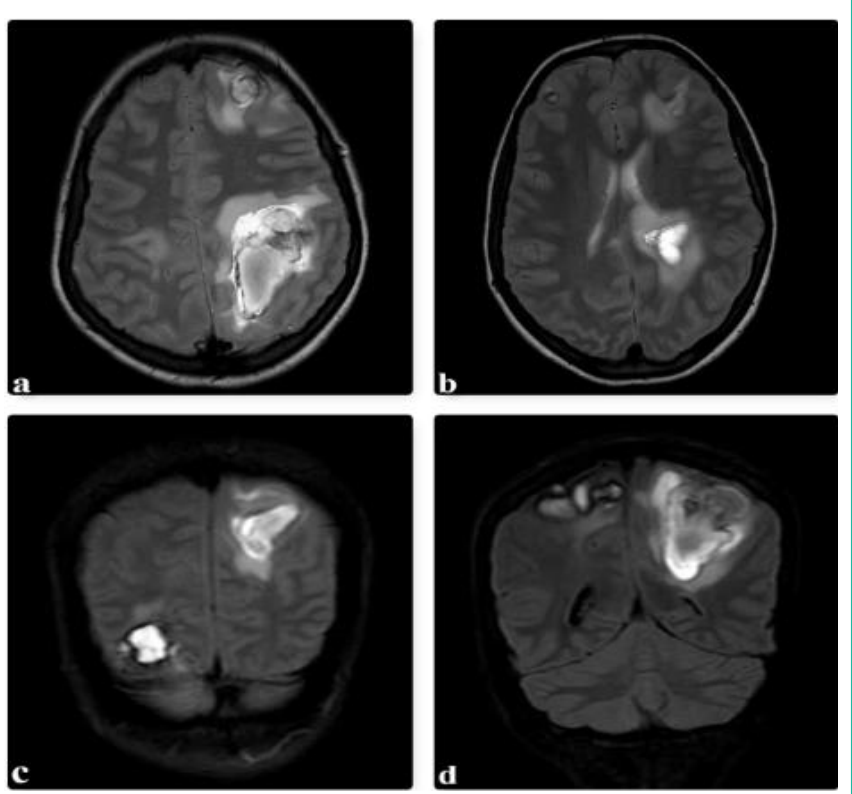

Figure 1: a,b: axial section in weighted sequences T2 c,d: Coronal T2 FLAIR-weighted sequence showing left frontal lesion, parietal bilateral and right occipital lesions with heterogeneous hyper signal, surrounded by perilesional edema, exerting a mass effect on adjacent cortical furrows and ventricular junction of the left lateral ventricle with discrete deviation of the structures of the median line on the right.
Austin J Radiol - Volume 5 Issue 1 - 2018

ISSN : 2473-0637 | www.austinpublishing group.com

Zakaria et al. @ All rights are reserved
Citation: Zakaria T, Firdaous T, Basma M, Meriem F and Mohamed J. Cerebral Metastasis Revealing a Choriocarcinoma: Case Report. Austin J Radiol. 2018; 5(1): 1077. 

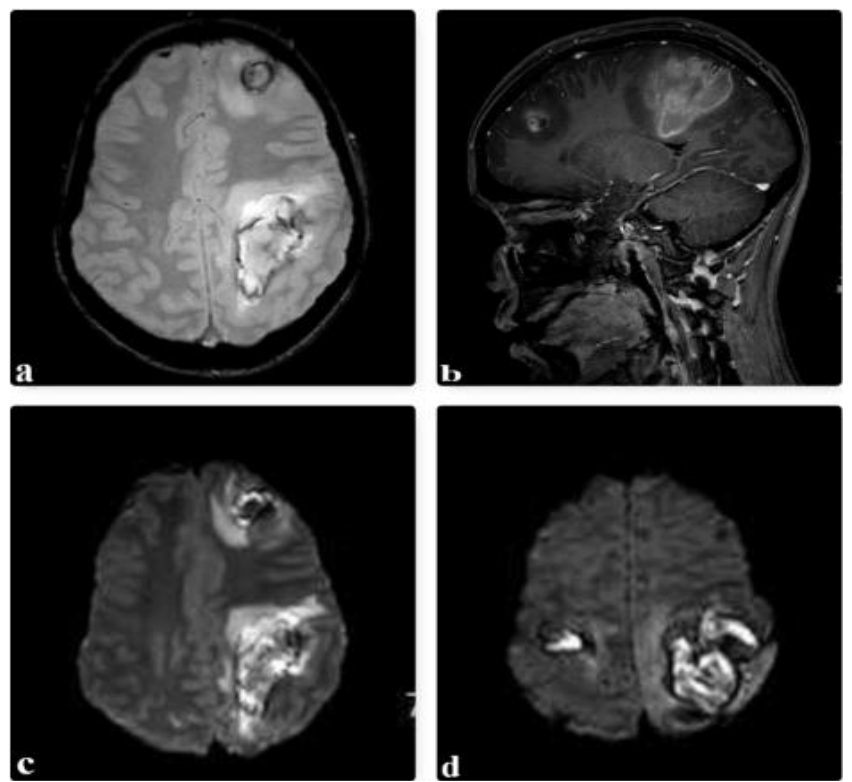

Figure 2: a: axial section in T2* sequences showing hyper-signal of left frontal and parietal lesions. b: Sagittal section in T1 weighted sequences with gadolinium injection showing peripheral contrast enhancement of lesions. c; d: DWI 1000 diffusion sequences, hyper signal lesions with ADC increase.

40 years or less old than 20 years [3], a history of a hydatiform mole, an abortion or a normal pregnancy [4], low socioeconomic status and malnutrition [5].

Clinically, metrorrhagia is the most frequently found sign, sometimes associated with pelvic pain; sometimes and as in our case, symptoms related to the seat of metastases come first [6]. Metastasis can occur in the lungs, vagina, kidneys, brain and ovaries. At the cerebral level, metastasis is found in 10 to $20 \%$ of cases of choriocarcinoma, they often take on the appearance of an intracerebral or subdural hematoma [7] (Figure 2c,d).

$\beta$-hCG blood test is the essential element of the diagnosis. The association of a metastatic pathology with a high level of $\beta$-hCG and an obstetrical history, in a woman during a period of genital activity is enough to make the diagnosis of choriocarcinoma [4].

Transabdominal ultrasound is the reference examination; it has a diagnostic interest and also prognostic by the ability to anticipate patients who will develop resistance to chemotherapy. Computed tomography remains key test for assessing the extent of the tumor in the chest and abdomen; Magnetic resonance imaging is useful in cerebral and pelvic exploration while evaluating the vascularization, myometrial and parametrial extension of the tumor [8].

The FIGO and WHO scores are used to assess prognosis and to have a therapeutic orientation.

Patients with brain metastasis are considered high risk patients; the standard of care in this category is a poly-chemotherapy EMACO (etoposide, methotrexate, actinomycin D, cyclophosphamide, and vincristine); surgical treatment is indicated in case of solitary metastases and the use of radiotherapy remains controversial [7].

\section{Conclusion}

Cerebral metastasis of choriocarcinomas is of poor prognosis; they must be suspected of any brain damage associated with a high $\beta$-hCG level in a woman during a period of genital activity in order to develop a rapid and adequate care.

\section{References}

1. Altieri A, Franceschi S, Ferlay J, Smith J, La Vecchia C. Epidemiology and aetiology of gestational trophoblastic diseases. Lancet Oncol. 2003; 4: 670678.

2. Khabouze S, Erchidi IE, Bouchikhi C, Chahtane A, Kharbach A, Chaoui A. [Gestational trophoblastic diseases. Apropos of 105 cases]. Gynecol Obstet Fertil. 2002; 30: 42-49.

3. Dreyfus M, Tissier I, Philippe E. [Gestational trophoblastic diseases. Classification, epidemiology and genetic data]. J Gynecol Obstet Biol Reprod (Paris). 2000; 29: 125-130.

4. Droz JP, Lhomme C. Gestational trophoblastic tumors. Rev Prat. 1992; 42 817-822.

5. Berkowitz RS, Goldstein DP. Chorionic tumors. N Engl J Med. 1996; 335: 1740-1748.

6. Chien JC, Hsiao YL, Lin SE, Chan WP. Off-midline retroperitonea choriocarcinoma presenting as neurologic symptoms. Eur J Gynaecol Oncol. 2011; 32: 343-346.

7. Dadlani R, Furtado SV, Ghosal N, Prasanna KV, Hegde AS. Unusual clinica and radiological presentation of metastatic choriocarcinoma to the brain and long-term remission following emergency craniotomy and adjuvant EMA-CO chemotherapy. J Cancer Res Ther. 2010; 6: 552-556.

8. Allen SD, Lim AK, Seckl MJ, Blunt DM, Mitchell AW. Radiology of gestational trophoblastic neoplasia. Clin Radiol. 2006; 61: 301-313.
Austin J Radiol - Volume 5 Issue 1 - 2018

ISSN : 2473-0637 | www.austinpublishing group.com

Zakaria et al. (C) All rights are reserved
Citation: Zakaria T, Firdaous T, Basma M, Meriem F and Mohamed J. Cerebral Metastasis Revealing a Choriocarcinoma: Case Report. Austin J Radiol. 2018; 5(1): 1077. 